\title{
Olive oil intake in relation to cardiovascular diseases
}

\author{
By Antonis Zampelas ${ }^{1}$ and Anthony G. Kafatos ${ }^{2^{*}}$ \\ 'Department of Nutrition and Dietetics, Harokopio University, Athens \\ ${ }^{2}$ Preventive Medicine and Nutrition Clinic, University of Crete School of Medicine, Athens \\ "Corresponding author: Dr. Anthony G. Kafatos \\ Email: kafatos@med.uoc.gr
}

\section{CONTENTS}

1. INTRODUCTION

2. EPIDEMIOLOGICAL STUDIES AND CLINICAL TRIALS

3. METABOLIC STUDIES

3.1. Plasma lipid levels

3.2. LDL oxidation

3.3. Anti-thrombotic properties

3.4. Markers of inflammation and infection

4. CONCLUSION

REFERENCES

\section{RESUMEN}

La ingesta de aceite de oliva en relación a las enfermedades cardiovasculares.

La aterosclerosis es el componente principal en la patogénesis de la enfermedad arterial coronaria (CAD). Diversos estudios epidemiológicos, clínicos y metabólicos indican la existencia de una asociación entre la ingesta de aceite de oliva (virgen extra) y una menor manifestación de CAD. El aceite de oliva es uno de los componentes esenciales de la dieta Mediterránea, es rico en ácido oleico (representa el $29 \%$ de la ingesta calórica diaria) y en antioxidantes (vitamina $E$ y polifenoles). Tiene efectos beneficiosos al reducir el riesgo cardiovascular relacionado con la concentración plasmática de LDL, la relación LDL:HDL, y la oxidación de las LDL. Además, el aceite de oliva contribuye a la regulación de los sistemas de coagulación y fibrinolisis (FVII, PAI-1, XIlc y XIla). Estas observaciones reafirman la importancia de las grasas de la dieta para las funciones vitales en el organismo y la prevención de CAD, donde el aceite de oliva ha de considerarse como un elemento nutricional determinante.

PALABRAS-CLAVE: Aceite de oliva; Ácidos grasos monoinsaturados; Enfermedad cardiovascular; Lipoproteínas; Oxidación de LDL; Hemostasia; Dieta Mediterránea.

\section{SUMMARY}

Olive oil intake in relation to cardiovascular diseases.

Atherosclerosis is the principal contributor to the pathogenesis of coronary artery disease (CAD). Epidemiological, clinical and metabolic studies have reported protective associations between (extra virgin) olive oil consumption and CAD. As a key component of the Mediterranean diet, olive oil is a rich source of oleic acid, making up about $29 \%$ of the daily dietary caloric intake, and antioxidants (vitamin E and phenolic compounds). Olive oil has beneficial effects by reducing LDL plasma concentration, the LDL cholesterol:HDL cholesterol ratio, and protecting LDL against oxidation. The progress of atherosclerosis and the risk of thrombo-embolic episodes could also be decreased through the reduction in plasma clotting factors levels, including FVIIc, PAI-1, XIIc and XIla. The findings reaffirm low-moderate fat policies for optimum health, within which olive oil appears to be an important component of the diet.

KEY-WORDS: Olive oil; Monounsaturated fatty acids; Cardiovascular disease; Lipoproteins; LDL oxidation; Haemostasis; Mediterranean diet.

\section{INTRODUCTION}

Doctors such as Galen, Hippocrates and Dioscorides (Viola and Audisio, 1987) acknowledged the therapeutic effects of olive oil since antiquity. Olive oil is extracted from the drupes of Olea Europaea, which is a tree widely grown in areas of southern Europe, hence its name, and nowadays, approximately $98 \%$ of the existing olive trees are being cultivated in the wider Mediterranean basin.

Olive oil intake differs among the Mediterranean countries. In the island of Crete, $29 \%$ of the caloric intake from the diet was derived from the consumption of olive oil (Keys, 1980) and this high consumption is probably the most important difference between the Cretan Mediterranean diet and the diets of the other Mediterranean countries (Table 1). It is noteworthy that in the Italian and Spanish traditional diets the daily dietary intake of olive oil is approximately $15-20 \mathrm{~g}$ but in the Cretan diet is much higher and it reaches $70 \mathrm{~g}$.

One of the beneficial properties of olive oil is the reduction of the risk of coronary artery disease (CAD) through the decrease in plasma cholesterol and the possible increase of HDL cholesterol levels, the decrease of LDL susceptibility to oxidation and the decrease in thrombogenic factors such as factor VII. The purpose of this article is to review the epidemiological, clinical and metabolic studies, which investigated the effects of olive oil and its constituents on risk factors for developing CAD.

\section{EPIDEMIOLOGICAL STUDIES AND CLINICAL TRIALS}

The interest of olive oil as a cardioprotective food arose from the results of the Seven Countries Study (Keys, 1970). This study started in 1960's and it 
Table 1

Nutrient composition of traditional Cretan Mediterranean diet and other Western type diets [average daily nutrient intake as percentage (\%) of total dietary caloric intake]

\begin{tabular}{|c|c|c|c|c|c|c|c|}
\hline Nutrient & $\begin{array}{c}\text { Cretan } \\
\text { diet }\end{array}$ & $\begin{array}{c}\text { British } \\
\text { diet }\end{array}$ & $\begin{array}{c}\text { Dutch } \\
\text { diet }\end{array}$ & $\begin{array}{c}\text { American } \\
\text { diet }\end{array}$ & $\begin{array}{c}\text { EU } \\
\text { Recommend } \\
\text { ations* }^{*}\end{array}$ & $\begin{array}{c}\text { Step } 1 \text { AHA } \\
\text { diet }^{\star *}\end{array}$ & $\mathrm{TLC}^{\star \star \star}$ \\
\hline Protein & 12 & 13 & 14 & 15 & & 15 & $\sim 15$ \\
\hline Fat & 43 & 41 & 36 & 38 & $20-35$ & 30 & $25-35$ \\
\hline Saturated & 10 & 17 & 15 & 18 & $7-10$ & 10 & $<7$ \\
\hline Monounsaturated & 23 & 14 & 12 & 10 & $10-15$ & 10 & up to 20 \\
\hline Polyunsaturated & 3 & 7 & 6 & 10 & $<7-8$ & 10 & up to 10 \\
\hline $\begin{array}{l}\text { Carbohydrates } \\
\text { Alcohol }\end{array}$ & 46 & $\begin{array}{l}43 \\
10\end{array}$ & $\begin{array}{l}49 \\
2\end{array}$ & 47 & $\begin{array}{l}>55-75 \\
24-36 \mathrm{~g}\end{array}$ & 55 & $50-60$ \\
\hline $\begin{array}{l}\text { Cholesterol } \\
\text { Dietary fiber }\end{array}$ & $180 \mathrm{mg}$ & & $\begin{array}{c}310 \mathrm{mg} \\
30 \mathrm{~g}\end{array}$ & $500 \mathrm{mg}$ & $\begin{array}{c}<300 \mathrm{mg} \\
>25 \mathrm{~g}\end{array}$ & $250 \mathrm{mg}$ & $\begin{array}{l}<200 \mathrm{mg} \\
20-30 \mathrm{~g}\end{array}$ \\
\hline
\end{tabular}

* Eurodiet project (Working Party 1: Final Report, 2001).

** Diet recommended by the American Heart Association (AHA), Adult Treatment Panel (ATP) II for the treatment of increased plasma lipid levels, such as cholesterol [Summary of the second report of the National Cholesterol Education Program (NCEP) Expert Panel on Detection, Evaluation, and Treatment of High Blood Cholesterol in Adults (Adult Treatment Panel II). (2003). JAMA, 269, 3015-3023].

*** Diet recommended by the American Heart Association (AHA), Adult Treatment Panel (ATP) III for the treatment of increased plasma lipid levels, such as cholesterol (Expert Panel, 2001).

compared the incidence of CAD and the life styles of populations from 7 countries, namely USA, the Netherlands, Finland, Japan, Yugoslavia, Italy and Greece. This study showed for the first time, that the Greek population from Crete had very low morbidity and mortality rates from CAD compared to the populations from the other countries. Additionally, Cretans were found to have lower plasma cholesterol levels than the Americans and this difference was speculated that it might have contributed to the observed differences in the prevalence of CAD in these two countries (Christakis et al., 1965). Differences between the American and the Cretan cohorts were also observed in the adipose tissue fatty acid composition. In particular, adipose tissue of the Cretans had a higher concentration in monounsaturated fatty acids (MUFA) than the adipose tissue of the American cohort. This observation was an indication that the traditional Cretan diet was high in MUFA, which were mainly coming from olive oil consumption.
In the 7 Countries Study, it was also observed that the Cretan cohort had relatively higher plasma cholesterol levels than the Italian and Yugoslavian, but the mortality rates from CAD remained lower even 25 years after the beginning of the study (Kromhout et al., 1995) and even for the same plasma cholesterol levels, the risk for developing CAD was three times lower in the Mediterranean populations in comparison to USA and the Northern European populations (Verschuren et al., 1995). The last two observations could indicate that factors such as diet and its components could influence the risk for developing $\mathrm{CAD}$ irrespective plasma cholesterol levels. However, plasma cholesterol levels were not correlated with the dietary MUFA intake, and subsequently olive oil consumption.

In a major secondary prevention trial, the Lyon Diet Heart Study (De Longeril et al., 1994), it was observed that deaths of patients with acute myocardial infarction (AMI) were dramatically decreased when patients were on a Cretan Mediterranean diet enriched with $\alpha$-linolenic acid, 
compared to controls who followed a diet recommended by American Heart Association (Renaud et al., 1995; De Longeril et al., 1996; 1998; 1999). More specifically, 605 French volunteers, who survived of a first MI, were randomized into either a control or a Cretan Mediterranean diet group. After 27 months of follow-up, 16 cardiac deaths were observed in the Control and only three in the Cretan Mediterranean diet group and the risk of new major cardiac events was reduced by $73 \%$ in the Mediterranean diet group. Moreover, in the later group, dietary intake of oleic (18:1n-9) and $\alpha$-linolenic (18:3n-3) acids as well as dietary fiber, vitamins $E$ and $C$ were increased, whereas, dietary saturated fatty acid (SFA) intake was decreased (De Longeril et al., 1998). Therefore, the beneficial effect of the Cretan Mediterranean diet could be attributed partly to olive oil intake.

In another case-control study in Spain (171 patients with first acute AMI and 171 hospital-matched controls), the exposure to the upper quintile of energy-adjusted olive oil (median intake: $54 \mathrm{~g} /$ day) was associated with a $82 \%$ relative reduction in the risk of a first $\mathrm{AMI}$ after adjustment for dietary and non-dietary cofounders (Fernandez-Jarne et al., 2002). The same researchers quantified the risk reduction of incident MI provided by a Mediterranean dietary pattern, by creating a score (Martinez-Gonzalez et al., 2002). Six food items were considered protective, namely olive oil, fiber, fruits, vegetables, fish and alcohol and 2 non-protective namely meat/meat products and items with high glycemic load (white bread, pasta, rice). It was observed that a high score, which means an adherence to the Mediterranean diet, was associated with low odds ratio of Ml.

However, in a large prospective study, involving 22,043 adults in Greece, even though a higher adherence to Mediterranean diet was associated with a reduction in total mortality and death from coronary heart disease, associations between individual food groups, including olive oil, and total mortality were not statistically significant (Trichopoulou et al., 2003). It is though noteworthy that in analyses adjusted for age, sex, years of education, smoking status, body mass index, waist-to-hip ratio, energy expenditure score and total energy intake, the only individual measures that were predictive of total mortality were the intake of fruits and nuts and the ratio of monounsaturated to saturated lipids. In addition, the inverse association between the Mediterranean diet score and total mortality was evident irrespective of sex, smoking status, level of education, body mass index, waist-to-hip ratio and level of physical activity. The presence of weak associations between individual components of the Mediterranean diet and total mortality could be due to the fact that there may be interactions between these components that may be difficult to detect, and that the effects of single nutrients may be too small but the cumulative effects substantial (Trichopoulou et al., 2003; Hu, 2003).

\section{METABOLIC STUDIES}

\subsection{Plasma lipid levels}

Numerous studies suggest that the beneficial effects of olive oil on plasma lipid levels are partly due to its MUFA content and the main MUFA of olive oil, oleic acid, is now widely known to exert hypocholesterolemic properties, compared to SFA. More specifically, in a study which compared the effects of SFA, MUFA and polyunsaturated fatty acids (PUFA) on plasma lipid levels, MUFA decreased LDL cholesterol levels, to the same extent as PUFA (Mattson and Grundy, 1985) but they also decreased HDL cholesterol levels less often than PUFA. More recently, when two diets different in fatty acid composition were given to volunteers with family history of CAD, the MUFA rich diet decreased plasma cholesterol and LDL cholesterol levels, and consequently improved the lipid profile, compared to the diet rich in SFA (Williams et al., 1999). In the same study, it was also observed that HDL cholesterol levels were not altered, and moreover, the LDL cholesterol:HDL cholesterol ratio was decreased.

One of the populations that were investigated in the 7 Countries Study was the Dutch population. When the effects of a high MUFA diet (15\% of the daily dietary caloric intake) on plasma lipid levels were compared with the effects of the average diet of the Dutch volunteers ( $11 \%$ of the daily dietary caloric intake in the form MUFA), an $18 \%$ reduction in plasma LDL cholesterol levels was observed, even with this small increase in dietary MUFA intake (Mensink and Katan, 1989). This reduction in plasma LDL cholesterol levels was even greater than the $13 \%$ reduction, which was observed following a diet rich in PUFA. The investigators concluded that a diet rich in MUFA could be at least as beneficial as a diet rich in PUFA in lowering plasma cholesterol levels. In contrast, a small decrease in plasma HDL cholesterol levels was observed in men, at the end of both dietary periods, but not in women. However, the high MUFA diet resulted in a better plasma lipemic improvement since the LDL:HDL ratio was lower than after the PUFA rich diet.

Apart from studies in European populations, similar interventions have been carried out in American cohorts. In one of the recent studies in American volunteers, the average American diet (38\% fat, 18\% SFA, 10\% MUFA, 10\% PUFA, 47\% carbohydrate, $15 \%$ protein, $500 \mathrm{mg}$ cholesterol) was compared with the diet that American Heart 
Association recommended at that time (Step I diet) for lowering plasma lipid levels (31.5\% fat, 9.9\% SFA, $11.3 \%$ MUFA, $10.3 \%$ PUFA, $51.7 \%$ carbohydrate, $16.6 \%$ protein, $241 \mathrm{mg}$ cholesterol), and with another diet enriched with MUFA, which also increased the total fat intake (37.3\% fat, 9.2\% SFA, $17.8 \%$ MUFA, $10.3 \%$ PUFA, $46.2 \%$ carbohydrate, $16.2 \%$ protein, $215 \mathrm{mg}$ cholesterol) (Ginsberg et al., 1990). It was observed that the MUFA rich diet was as beneficial in lowering plasma lipids (total and LDL cholesterol), as the American Heart Association diet. A closer look, however, in the results, would indicate that there was a trend towards a bigger reduction in total cholesterol and LDL cholesterol levels at the end of the MUFA diet than at the end of the Step I diet, but the statistical power was not enough to permit direct comparison between the two diets. Both diets did not alter significantly HDL cholesterol and triglycerides levels compared to the control average American diet.

In mildly hypercholesterolemic subjects, a 6 weeks MUFA diet decreased total cholesterol and apolipoprotein B levels and the addition of $n-3$ fatty acids did not decrease serum lipids any further (Puiggros et al., 2002). However, the $n$-3 diet increased lipoperoxide levels in isolated native LDL, which would indicate higher LDL oxidation. On the other hand, Pedersen et al. (2000) reported beneficial effects of rapeseed oil compared to olive oil diets in plasma lipids although at the end of the olive oil diet period higher concentrations of $\mathrm{HDL}_{2}$ and large and buoyant LDL were observed.

In the postprandial state, it was observed that Northern Europeans (British and Irish) clear fat from blood circulation at a slower rate than Cretans after fat containing meals (Zampelas et al., 1998). The faster rate of absorption and subsequent metabolism of fat, may partly explain the decreased risk for developing CAD in Cretans. In addition, in a British cohort, even a small increase in MUFA in the diet (from $12 \%$ to $18 \%$ of dietary daily caloric intake) resulted to a $14 \%$ decrease in plasma LDL cholesterol levels and a maintenance of plasma HDL cholesterol levels compared to their usual habitual diet which was rich in SFA (Williams et al., 1999). This dietary intervention which lasted for 8 weeks resulted also in an improvement of the postprandial plasma triglycerides response, following a meal with specific fatty acid composition (Roche et al., 1998).

Studies also showed that fatty acid composition of acute test meals does not seem to affect postprandial plasma lipid levels responses (Jackson et al., 1999; Nielsen et al., 2000). In another study, extra virgin olive oil intake attenuated postprandial triglyceride concentration and increased triglyceride disappearance in triglyceride-rich lipoproteins compared to high oleic sunflower oil, suggesting that MUFA content may not be the only predictor of postprandial metabolism of triglycerides (Abia et al., 2001). Mekki et al. (2002) reported lower postprandial lipemia and chylomicron accumulation in the circulation of young healthy men following a test meal containing butter than meals containing either olive oil or sunflower oils. However $20 \%$ of fatty acids from butter are of short and medium chain and these fatty acids are not incorporated into chylomicrons and therefore interpretation of these results should be made with caution.

Olive oil has also beneficial properties on lipemic profile, compared to dietary carbohydrates. In particular, when a diet rich in olive oil $(24-28 \%$ of daily dietary caloric intake) was compared with a high carbohydrate diet $(60 \%$ as energy), the high carbohydrate diet resulted to a decrease in plasma HDL cholesterol and an increase in triglyceride levels (Grundy, 1986; Mensink and Katan, 1987). Moreover, a diet rich in carbohydrates may cause adverse effects in the treatment of metabolic syndrome insulin resistance and subsequent type 2 diabetes. In particular, a diet high in carbohydrates may worsen the lipemic profile and deteriorate the already existing hyperglycemic response. Thus, a diet high in MUFA, such as commonly consumed in the Mediterranean region, appears to be the preferable diet for patients with the metabolic syndrome (Grundy, 1999).

The beneficial effects of MUFA in plasma lipid levels led to a consensus and the new guidelines of the National Cholesterol Education Program for the treatment of hypercholesterolemia in adults suggest a change in lifestyle factors (Therapeutic Lifestyle Changes, TLC). According to these new guidelines, dietary fat intake could be as high as $35 \%$ of the total energy intake and MUFA should provide up to $20 \%$ of energy (Expert Panel, 2001; 2002). These guidelines also suggest that for the treatment of the metabolic syndrome, diets even higher in fat content could be followed providing that the additional fat is in the form of MUFA. These guidelines are more liberal in the dietary fat intake recommendations than the Adult Treatment Panel (ATP) II guidelines (Step I and Step II diets), and it is also obvious that special emphasis is given in the dietary MUFA intake.

Oleic acid is probably oxidized in a different degree than saturated fats. In a recent study, stable isotope tracer methodologies, in combination with indirect calorimetry, were used to determine the oxidation of dietary fats in subjects fed a MUFA diet and a SFA diet (Jones et al., 1999). The results from this study suggested that fatty acid composition of background diet may influence the relative proportion of fat oxidation, that is attributed to exogenous (i.e. dietary) and endogenous fat oxidation. It was suggested that even a relatively small increase in SFA content of a diet, compared to MUFA, could decrease exogenous fat oxidation. 


\subsection{LDL oxidation}

Olive oil has beneficial effects against LDL oxidation. It is now well known that PUFA increase LDL oxidation, compared to MUFA (Reaven et al., 1991; 1993). In the Jerusalem Study, a PUFA rich diet lead to increased LDL oxidation compared to a MUFA rich diet (Berry et al., 1991). In addition, LDL was less susceptible to lipid peroxidation in volunteers with mildly elevated plasma cholesterol levels after following a diet rich in MUFA than in PUFA (Reaven et al., 1993). In a more recent study, it was also demonstrated that low fat, such as the Step II diet of the American Heart Association, and high MUFA diets have similar effects on LDL oxidative resistance by lowering oxidation rates and this was associated with a lower PUFA content in LDL (Hargrove et al., 2001).

Another factor which influences LDL oxidation is the presence of antioxidants, such as vitamin $E$ and polyphenols. Extra virgin olive oil composition is unique in this respect because it is rich in both MUFA, which have increased resistance to oxidation, and vitamin $\mathrm{E}$ and phenolic compounds, such as flavonoids, which decrease even further the susceptibility of LDL to oxidation. Extra virgin olive oil consists of $55-85 \%$ oleic acid, tocopherols (5-10 $\mathrm{mg} / 100 \mathrm{~g}, 95 \% \quad \alpha$-tocopherol), carotenoids (1-2 $\mathrm{mg} / 100 \mathrm{~g}$ ), phenolic compounds such as oleuropein (20-500 mg/L), and phytosterols (98-185 mg/100 g) (Stark and Madar, 2002). It has already been observed that an increase in vitamin $E$ levels in blood circulation decreases the risk for developing CAD (Stampfer et al., 1993). The daily vitamin $\mathrm{E}$ and other antioxidant's requirements seem now to be dependent on the degree of unsaturation of dietary fatty acids and their concentration in blood circulation. LDL, formed following a diet rich in MUFA, tend to be resistant to lipid peroxidation (Steinberg and Witztum, 1990; Mata et al., 1997). Even though the extent by which the balance between dietary antioxidants and the degree of fatty acid unsaturation influences the risk for developing CAD is still unknown, the high concentration of vitamin $\mathrm{E}$ and the predominance of MUFA in olive oil seem to contribute to the low prevalence of CAD. However, the issue of vitamin $E$ as a protective vitamin against CAD remains unresolved. Although epidemiological (Gey et al., 1991; Stampfer et al., 1993; Rimm et al., 1993) and metabolic studies (Esterbauer et al., 1991; Green et al., 1998) showed beneficial effects of vitamin $E$ on CAD mortality rates and risk factors of CAD respectively, in the secondary prevention, vitamin E supplementation failed to show any benefit (Stephens et al., 1996; Mitchinson et al., 1999). It could be argued that the effect is dose- and time-dependent and in order to see any benefit one should ingest small amounts for long time periods and not large for short time. Another explanation could be that there is a synergistic effect of $\alpha$-tocopherol with other antioxidants, such as polyphenols, in the diet. However, research is still necessary in this area.

Squalene is another minor constituent of olive oil (500-700 mg/kg). Squalene has been reported to inhibit the activity of HMG-CoA reductase, the key enzyme for cholesterol synthesis (Visioli and Galli, 2002).

In general, the beneficial effects of phenols which are present in extra virgin olive oil are considered to be partly through the inhibition of LDL oxidation (Visioli and Galli, 1998). The major phenolic compounds in extra virgin olive oil are oleuropein, hydroxytyrosol and tyrosol, and it is now well established that flavonoids and phenolic compounds are absorbed from the diet. There is evidence that their bioavailability in extra virgin olive oil, especially hydroxytyrosol bioavailability, is high since they are easily conveyed to the oil by the pressing of the drupe (Visioli and Galli, 2002; Tuck and Hayball, 2002). In vitro studies showed that olive oil phenolics could increase lag time of conjugated diene formation after copper-mediated LDL oxidation and inhibit thiobarbituric acid reactive substances after AAPH-initiated LDL oxidation (Fito et al., 2000; Leenen et al., 2002). This is in accordance with the results of a trial which showed a significant correlation of the lag phase of conjugated diene formation and the increase in plasma phenolic content at the end of a 4 weeks extra virgin olive oil supplementation period (20 g/day) (Masella et al., 2001). The differences observed were not correlated with LDL fatty acid composition or vitamin E content which suggests a protective effect of phenolic compounds of extra virgin olive oil against LDL oxidation. In contrast, no effect of olive oil phenols was observed on markers of oxidation in smokers (Moschandreas et al., 2002) which could indicate that smokers need higher intakes of antioxidants. Moreover, in another study, no difference in the resistance of $L D L$ and $\mathrm{HDL}$ to oxidation was observed between phenol-rich and phenol-poor extra virgin olive oil diets in healthy volunteers (Vissers et al., 2001). However, in this study the intake of olive oil was unrealistically high and the supplementation period was relatively short $(69 \mathrm{~g}$ for 3 weeks) and therefore intervention studies in physiological conditions would give further information regarding the effect of olive oil polyphenols on LDL susceptibility to oxidation.

\subsection{Anti-thrombotic properties}

Apart from its anti-atherogenic properties, olive oil has also anti-thrombotic properties. Although early findings showed an increase in factor VIlc 
Table 2

Effects of olive oil on biochemical parameters in blood circulation, which influence atherogenesis and thrombogenesis

\begin{tabular}{|l|c|}
\hline Parameter & Influence of olive oil \\
\hline Effect on atherogenesis & - \\
LDL-C & + \\
HDL-C & - \\
oxidized LDL & \\
& \\
Effect on thrombogenesis & - \\
FVII & - \\
PAI-1 & \\
\hline
\end{tabular}

following a high oleic acid meal (Oakley et al., 1998; Sanders et al., 1999), other studies demonstrated a beneficial effect of olive oil rich diets on haemostasis. Roche et al. (1998) found that a diet rich in MUFA reduces plasma factor VII levels, following the consumption of a test meal, and Larsen et al. (1999) observed that a 3-weeks olive oil diet lowers non-fasting mean and peak concentrations of FVIla than a sunflower oil diet (Kelly et al., 2001). In addition, a 16-weeks MUFA diet resulted in a less postprandial FVII activation and beneficial changes in whole-blood platelet aggregation in healthy young adults as compared to a SFA diet.

Another study compared the effects of a diet rich in MUFA on plasminogen activating inhibitor-1 (PAI-1) levels with the effects of a low fat diet on the same parameter (Lopez-Segura et al., 1996). PAl-1 inactivates the function of endogenous plasminogen activator in the tissues, which leads to thrombus breakdown and as a consequence, PAl- 1 increases the risk for developing thrombosis. This study indicated that a diet rich in PUFA decreased plasma PAI-1 levels and as a result the risk for thrombogenesis. Another, more recent study, indicated that oleic acid decreases plasma factor VII and PAI-1 levels, compared to palmitic acid (Temme et al., 1999). In contrast, work by Tholstrup et al. (1999) indicated no benefit from a MUFA diet on t-PA activity and PAI-1 antigen levels, which means that more research is necessary in this area. However, after comparing the response to a low-fat meal, with a high-fat meal, the later increased plasma factor VII levels, regardless of the fatty acid composition of the meal (Oakley et al., 1998) and therefore, it seems that the impact of dietary fat composition on fasting FVII concentrations is not as pronounced as the impact of total fat intake (Marckmann et al., 1998).
In another study, a 4-weeks olive oil diet decreased coagulation factors VIIc, XIlc, XIla, and Xc compared to a wash-in SFA diet in healthy individuals (Junker et al., 2001). In the same study the rapeseed oil diet did not have any effect and the sunflower oil diet decreased FXIlc, FXIla and FIXc. t-PA and PAI-1 were not influenced in the olive oil and sunflower oil diets and therefore fibrinolysis was not affected.

\subsection{Markers of inflammation and infection}

It is now well known that the immune system plays an important role in the inflammatory events leading to atherosclerosis. Animal studies have shown that olive oil suppresses natural killer cell activity (Yaqoob et al., 1994a), mitogen-stimulated proliferation (Yaqoob et al., 1994b; 1995) and expression of receptors for interleukin 2 and transferrin (Yaqoob et al., 1994b) in leucocytes. However, in a human trial it was also demonstrated that an 8-weeks olive oil diet decreased the expression of intercellular adhesion molecule 1 by peripheral blood mononuclear cells but did not affect natural killer cell activity or proliferation of mitogen-stimulated leucocytes (Yaqoob et al., 1998).

\section{CONCLUSION}

Olive oil and its constituents have beneficial effects on plasma lipid metabolism. The effects include decrease of LDL cholesterol and probable increase in HDL cholesterol levels. Apart from its effects on plasma lipid levels, olive oil, decreases LDL oxidation, rendering these lipoprotein particles less atherogenic (Table 2). The progress of atherosclerosis and the risk of thrombo-embolic 
episodes could also be decreased through the reduction in several plasma clotting factors levels such as FVIIc, XIlc and XIla. Finally, there is evidence that olive oil could affect parameters which play a role in the inflammation response.

The increase in olive oil intake to a level, similar to the one observed in the Cretan Mediterranean diet and its adoption as a wider European Union policy and recommendation for its citizens, would probably have a major impact in the annual production of olive oil which would have to reach 14,000 tons. This target is probably beyond the present capacity and would have land-use implications since olive oil production would have to displace pastures and the production of other crops (Gibney and Roche, 2001). However all these issues have to be considered when a public health nutrition policy is to be applied in such a wide range of populations taking into account their cultural and economic backgrounds.

\section{REFERENCES}

Abia, R., Pacheco, Y.M., Perona, J.S., Montero, E., Muriana, F.J.G., Ruiz-Gutierrez, V. (2001). The metabolic availability of dietary triacylglycerols from two high oleic oils during the postprandial period does not depend on the amount of oleic acid ingested by healthy men. J. Nutr., 131, 59-65.

Berry, E.M., Eisenberg, S., Haratz, D., Friedlander, Y., Norman, Y., Kaufmann, N.A., Stein, Y. (1991). Effects of diets rich in monounsaturated fatty acids on plasma lipoproteins-the Jerusalem Nutrition Study: high MUFAs vs high PUFAs. Am. J. Clin. Nutr., 53, 899-907.

Christakis, G., Severinghaus, E.L., Maldonado, Z., Kafatos, F., Hashim, S.A. (1965). Crete: A study in the metabolic epidemiology of coronary heart disease. Am. J. Cardiol., 15, 320-332.

De Longeril, M., Renaud, S., Mamelle, N., Salen, P., Martin, J.L., Monjaud, I., Guidollet, J., Toubol, P., Delaye, J. (1994). Mediterranean alpha-linolenic acid-rich diet in secondary prevention of coronary heart disease. Lancet, 343, 1454-1459.

De Longeril, M., Salen, P., Martin, J.L., Mamelle, N., Monjaud, I., Toubol, P., Delaye, J. (1996). Effect of a Mediterranean type of diet on the rate of cardiovascular complications on patients with coronary artery disease. Insights into the cardioprotective effect of certain nutrients. J. Am. Coll. Cardiol., 28, 1103-1108.

De Longeril, M., Salen, P., Martin, J.L., Monjaud, I., Boucher, P., Mamelle, N. (1998). Mediterranean dietary pattern in a randomized trial: prolonged survival and possible reduced cancer rate. Arch. Intern. Med., 158, 1181-1187.

De Longeril, M., Salen, P., Martin, J.L., Monjaud, I., Delaye, J., Mamelle, N. (1999). Mediterranean diet, traditional risk factors, and the rate of cardiovascular complications after myocardial infarction: final report of the Lyon Diet heart Study. Circulation, 99, 779-785.

Esterbauer, H., Dieber-Rotheneder, M., Striegl, G., Waeg, G. (1991). Role of vitamin $E$ in preventing the oxidation of low density lipoprotein. Am. J. Clin. Nutr., 53, 314S-321S.

Expert Panel on detection, evaluation and treatment of high blood cholesterol in adults. Executive summary of the third report of the National Cholesterol Education
Program (NCEP) Expert Panel on detection, evaluation and treatment of high blood cholesterol in adults (Adult Treatment Panel III). (2001). JAMA, 285, 2486-2497.

Expert Panel on detection, evaluation and treatment of high blood cholesterol in adults. $3^{\text {rd }}$ Report of the National Cholesterol Education Program. Final Report. National Institutes of Health, National Heart, Lung and Blood Institute, 2002.

Fernandez-Jarne, E., Martinez-Losa, E., PradoSantamaria, M., Brugarolas-Brufau, C., SerranoMartinez, M., Martinez-Gonzalez, M.A. (2002). Risk of first non-fatal myocardial infarction negatively associated with olive oil consumption: a case-control study in Spain. Intern. J. Epidemiol., 31, 474-480.

Fito, M., Covas, M.I., Lamuela-Raventos, R.M., Vila, J., Torrents, J., De la Torre, C., Marrrugat, J. (2000). Protective effect of olive oil and its phenolic compounds against low density lipoprotein oxidation. Lipids, 35, 633-638.

Gey, K.F., Puska, P., Jordan, P., Moser, U.K. (1991). Inverse correlation between plasma vitamin $\mathrm{E}$ and mortality from ischaemic heart disease in cross-cultural epidemiology. Am. J. Clin. Nutr., 53, 326S-334S.

Gibney, M.J., Roche, H.M. (2001). Nutrition policy issues and further research on the Mediterranean Diet: the importance of monounsaturated fatty acids. In: The Mediterranean Diet: constituents and health promotion. Eds Matalas AL, Zampelas A, Stavrinos V, Wolinski I, CRC Press Boca Ration, USA.

Ginsberg, H.N., Barr, S.L., Gilbert, A., Karmally, W., Deckelbaum, R., Kaplan, K., Ramakrishnan, R., Holleran, S., Dell, R.B. (1990). Reduction of plasma cholesterol levels in normal men on an American Heart Association Step 1 diet with added monounsaturated fat. N. Engl. J. Med., 322, 574-579.

Green, D., O'Driscoll, G., Rankin, J.M., Maiorana, A.J., Taylor, R.R. (1998). Beneficial effects of vitamin E administration on nitric oxide function in subjects with hypercholesterolaemia. Clin. Sci., 95, 361-367.

Grundy, S.M. (1986). Comparison of monounsaturated fatty acids and carbohydrates for lowering plasma cholesterol. N. Engl. J. Med., 314, 745-748.

Grundy, S.M. (1999). Dietary therapy of the metabolic syndrome and type II diabetes. Atherosclerosis, 144, $171 \mathrm{~A}$.

Hargrove, R.L., Etherton, T.D., Pearson, T.A., Harrison, E.H., Kris-Etherton, P.M. (2001). Low fat and high monounsaturated fat diets decrease human low density lipoprotein oxidative susceptibility in vitro. $J$. Nutr., 131, 1758-1763.

Hu, F.B. (2003). The Mediterranean Diet and mortality-olive oil and beyond. N. Engl. J. Med., 348, 2595-2596.

Jackson, K.G., Zampelas, A., Knapper, J.M.E., Culverwell, C.C., Wright, J., Gould, B.J., Williams, C.M. (1999). Lack of influence of test meal fatty acid composition on the contribution of intestinally-derived lipoproteins to postprandial lipaemia. Br. J. Nutr., 81, 51-57.

Jones, A.E., Smith, R.D., Kelly, C., Williams, C.M., Wootton, S.A. (1999). Oxidation of dietary fat is decreased on an isocaloric saturated fat diet compared with a monounsaturated fat diet. Atherosclerosis, 144, 171A.

Junker, R., Kratz, M., Neufeld, M., Erren, M., Nofer, J.R., Schulte, H., Nowak-Gottl, U., Assmann, G., Wahrburg, U. (2001). Effects of diets containing olive oil, sunflower oil or rapeseed oil on the haemostatic system. Thromb. Haemost., 85, 280-286. 
Kelly, C.N.M., Smith, R.D., Williams, C.M. (2001). Dietary monounsaturated fatty acids and haemostasis. Proc. Nutr. Soc., 60, 161-170.

Keys, A. (1970). Coronary heart disease in seven countries. Circulation, 41, 1-211.

Keys, A. (1980). Seven Countries: A multivariate analysis of death and coronary heart disease. Cambridge MA/London: Harvard University Press.

Kromhout, D., Menotti, A., Bloemberg, B., Aravanis, C., Blackburn, H., Buzina, R., Dontas, A.S., Fidanza, F., Glampaoli, S., Jansen, A., Karvonen, M., Katan, M., Nissinen, A., Nedeljkovic, S., Pekkanen, J., Pekkarinen, M., Punsar, S., Rasanen, L., Simic, B., Toshima, H. (1995). Dietary saturated and trans fatty acids and cholesterol and 25-year mortality from coronary heart disease: The Seven Countries Study. Prev. Med., 24, 308-315.

Larsen, L.F., Jespersen, J., Marckmann, P. (1999). Are olive oil diets antithrombotic? Diets enriched with olive, rapeseed or sunflower oil affect postprandial factor VII differently. Am. J. Clin. Nutr., 70, 976-982.

Leenen, R., Roodenburg, A.J.C., Vissers, M.N., Schuurbiers, J.A.E., van Putte, K.P., Wiseman, S.A., van de Put, F.H. (2002). Supplementation of plasma with olive oil phenols and extracts: influence on LDL oxidation. J. Agric. Food Chem., 50, 1290-1297.

Lopez-Segura, F., Velasco, F., Lopez-Miranda, J., Castro, P., Lopez-Pedrera, R., Blanco, A., Jimenez-Pereperez, J., Torres, A., Trujillo, J., Ordovas, J.M., Perez-Jimenez, F. (1996). Monounsaturated fatty-acid enriched diet decreases plasma plasminogen activator inhibitor type 1. Arterioscler. Thromb. Vasc. Biol., 16, 82-88.

Marckmann, P., Bladbjerg, E.M., Jespersen, J. (1998). Diet and blood coagulation factor VII - a key protein in arterial thrombosis. Eur. J. Clin. Nutr., 52, 75-84.

Martinez-Gonzalez, M.A., Fernandez-Jarne, E., SerranoMartinez, M., Marti, A., Martinez, J.A., Martin-Moreno, J.M. (2002). Mediterranean diet and reduction in the risk of first acute myocardial infarction: an operational healthy dietary score. Eur. J. Nutr., 41, 153-160.

Masella, R., Giovannini, C., Vari, R., Di Benedetto, R., Coni, E., Volpe, R., Fraone, N., Bucci, A. (2001). Effects of dietary virgin olive oil phenols on low density lipoprotein oxidation in hyperlipidemic patients. Lipids, 36, 1195-1202.

Mata, P., Varela, O., Alonso, R., Lahoz, C., De Oya, M., Badimon, L. (1997). Monounsaturated and polyunsaturated $n-6$ fatty-acid-enriched diets modify LDL oxidation and decrease human coronary smooth muscle cell DNA synthesis. Arterioscler. Thromb. Vasc. Biol., 17, 1088-1095.

Mattson, F., Grundy, S. (1995). Comparison of effects of dietary saturated, monounsaturated and polyunsaturated fatty acids on plasma lipids and lipoprotein in man. J. Lipid Res., 26, 194-202.

Mekki, N., Charbonnier, M., Borel, P., Leonardi, J., Juhel, C., Portugal, H., Lairon, D. (2002). Butter differs from olive oil and sunflower oil in its effects on postprandial lipemia and triacylglycerol-rich lipoproteins after single mixed meals in healthy young men. J. Nutr., 132, 3642-3649.

Mensink, R.P., Katan, M.B. (1987). Effect of monounsaturated fatty acids versus complex carbohydrates on high-density lipoproteins in healthy men and women. Lancet, 1, 122-125.

Mensink, R.P., Katan, M.B. (1989). Effect of a diet enriched with monounsaturated fatty acids on levels of LDL- and HDL-cholesterol in healthy women and men. N. Engl. J. Med., 321, 436-441.
Mitchinson, M.J., Stephens, N.G., Parsons, A., Bligh, E., Schonfeld, P.M., Brown, M.J. (1999). Mortality in the CHAOS trial. Lancet, 353, 381-382.

Moschandreas, J., Vissers, M.N., Wiseman, S., van Putte, K.P., Kafatos, A. (2002). Extra virgin olive oil phenols and markers of oxidation in Greek smokers: a randomized cross-over study. Eur. J. Clin. Nutr., 56, 1024-1029.

Nielsen, N.S., Marckmann, P., Hoy, C.E. (2000). Effect of meal fat quality on oxidation resistance of postprandial VLDL and LDL particles and plasma triacylglycerol level. Br. J. Nutr., 84, 855-863.

Oakley, F.R., Sanders, T.A., Miller, G.J. (1998). Postprandial effects of an oleic acid-rich oil compared with butter on clotting factor VII and fibrinolysis in healthy men. Am. J. Clin. Nutr., 68, 1202-1207.

Pedersen, A., Baumstark, M.W., Marckmann, P., Gylling, H., Sandstrom, B. (2000). An olive-oil rich diet results in higher concentrations of LDL cholesterol and a higher number of LDL subfraction particles than rapeseed oil and sunflower oil diets. J. Lipid Res., 41, 1901-1911.

Puiggros, C., Chacon, P., Armadans, L.I., Clapes, J., Planas, M. (2002). Effects of oleic-rich and omega-3-rich diets on serum lipid pattern and lipid oxidation in mildly hypercholesterolemic patients. Clin. Nutr., 21, 79-87.

Reaven, P., Parthasarathy, S., Grasse, B.J., Miller, E., Almazan, F., Mattson, F.H., Khoo, J.C., Steinberg, D., Witztum, J.L. (1991). Feasibility of using oleate-rich diet to reduce the susceptibility of LDL to oxidative modification in humans. Am. J. Clin. Nutr., 54, 701-706.

Reaven, P., Parthasarathy, S., Grasse, B.J., Miller, E., Steinberg, D., Witztum, J.L. (1993). Effects of oleate-rich and linoleate-rich diets on the susceptibility of low density lipoprotein to oxidative modification in mildly hypercholesterolemic subjects. J. Clin. Invest., 91, 668-676.

Renaud, S., De Longeril, M., Delaye, J., Guidollet, J., Jacquard, F., Mamelle, N., Martin, J.L., Monjaud, I., Salen, P., Toubol, P. (1995). Cretan Mediterranean diet for prevention of coronary heart disease. Am. J. Clin. Nutr., 61, 1360S-1367S.

Rimm, E.B., Stampfer, M.J., Ascherio, A., Giovannucci, E., Colditz, G.A., Willett, W.C. (1993). Vitamin E consumption and the risk of coronary heart disease in men. N. Engl. J. Med., 328, 1450-1456.

Roche, H., Zampelas, A., Knapper, J.M.E., Webb, D., Brooks, C., Jackson, K.G., Wright, J., Gould, B.J., Kafatos, A., Gibney, M.J., Williams, C.M. (1998). Effect of long-term olive oil dietary intervention on postprandial triacylglycerol and factor VII metabolism. Am. J. Clin. Nutr., 68, 552-560.

Sanders, T.A.B., de Grassi, T., Miller, G.J., Humphries, S.E. (1999). Dietary oleic and palmitic acids and postprandial factor VII in middle-aged heterozygous and homozygous for factor VII R353Q polymorphism. Am. J. Clin. Nutr., 69, 220-225.

Stampfer, M., Hennekens, C., Manson, J.E., Colditz, G.A., Rosner, B., Willett, W.C. (1993). Vitamin E consumption and the risk of coronary disease in women. N. Engl. $J$. Med., 328, 1444-1449.

Stark, A.H., Madar, Z. (2002). Olive oil as a functional food: epidemiology and nutritional approaches. Nutr. Rev., 60, 170-176.

Steinberg, D., Witztum, J. (1990). Lipoproteins and atherogenesis: current concepts. JAMA, 264, 3047-3052.

Stephens, N.G., Parsons, A., Sconfield, P.M., Kelly, F., Cheeseman, K., Mitchinson, M.J. (1996). Randomized 
controlled trial on vitamin $\mathrm{E}$ in patients with coronary disease. Cambridge Heart Antioxidant Study (CHAOS). Lancet, 347, 781-786.

Temme, E.H., Mensink, R.P., Hornstra, G. (1999). Effects of diets enriched in lauric, palmitic or oleic acids on blood coagulation and fibrinolysis. Thromb. Haemost., 81, 259-263.

Tholstrup, T., Marckmann, P., Hermansen, J., Holmer, G., Sandstrom, B. (1999). Effect of a modified dairy fat on fasting and postprandial haemostatic variables in healthy young men. Br. J. Nutr., 82, 105-113.

Trichopoulou, A., Costacou, T., Bamia, C., Trichopoulos, D. (2003). Adherence to a Mediterranean Diet and survival in a Greek population. N. Engl. J. Med., 348, 2599-2608.

Tuck, K.L., Hayball, P.J. (2002). Major phenolic compounds in olive oil: metabolism and health effects. J. Nutr. Biochem., 13, 636-644.

Verschuren, W.M., Jacobs, D.R., Bloemberg, B.P., Kromhout, D., Menotti, A., Aravanis, C., Blackburn, H., Buzina, R., Dontas, A.S., Fidanza, F. (1995). Serum total cholesterol and long-term coronary heart disease mortality in different cultures. Twenty-five-year follow-up of the seven countries study. JAMA, 274, 131-136.

Viola, P., Audisio, M. (1987). International Olive Oil Council. Madrid.

Visioli, F., Galli, C. (1998). The effect of minor constituents of olive oil on cardiovascular disease: new findings. Nutr. Rev., 56, 142-147.

Visioli, F., Galli, C. (2002). Biological properties of olive oil phytochemicals. Crit. Rev. Food Sci. Nutr., 42, 209-221.
Vissers, M.N., Zock, P.L., Wiseman, S.A., Meyboom, S., Katan, M.B. (2001). Effect of phenol-rich extra virgin olive oil on markers of oxidation in healthy volunteers. Eur. J. Clin. Nutr., 55, 334-341.

Williams, C.M., Knapper, J.M.E., Webb, D., Zampelas, A., Tredger, J.A., Wright, J., Meijer, G., Calder, P.C., Yaqoob, P., Roche, H., Gibney, M.J. (1999). Cholesterol reduction using manufactured foods high in monounsaturated fatty acids, a randomized cross-over study. Br. J. Nutr., 81, 439-446.

Working Party 1: Final Report (2001). European diet and public health: the continuing challenge. Public Health Nutr., 4, 275-292.

Yaqoob, P., Knapper, J.A., Webb, D.H., Williams, C.M., Newsholme, E.A., Calder, P.C. (1998). Effect of olive oil on immune function in middle-aged men. Am. J. Clin. Nutr., 67, 129-135.

Yaqoob, P., Newsholme, E.A., Calder, P.C. (1994a). Inhibition of natural killer cell activity by dietary lipids. Immunol. Lett., 41, 241-247.

Yaqoob, P., Newsholme, E.A., Calder, P.C. (1994b). The effect of dietary lipid manipulation on rat lymphocyte subsets and proliferation. Immunology, 82, 603-610.

Yaqoob, P., Newsholme, E.A., Calder, P.C. (1995). The effect of fatty acids on leucocyte subsets and proliferation in whole blood. Nutr. Res., 15, 279-287.

Zampelas, A., Roche, H., Knapper, J.M.E., Jackson, K.G., Tornaritis, M., Hatzis, C., Gibney, M.J., Kafatos, A., Gould, B.J., Wright, J., Williams, C.M. (1998). Differences in postprandial lipaemic response between Northern and Southern Europeans. Atherosclerosis, 139, 83-93. 